\title{
Phytoplankton assemblages in a complex system of interconnected reservoirs: the role of water transport in dispersal
}

\section{Ren Hu, Xueke Duan, Liang Peng, Boping Han \& Luigi Naselli-Flores}

\section{Hydrobiologia}

The International Journal of Aquatic Sciences

ISSN 0018-8158

Volume 800

Number 1

Hydrobiologia (2017) 800:17-30

DOI 10.1007/s10750-017-3146-y

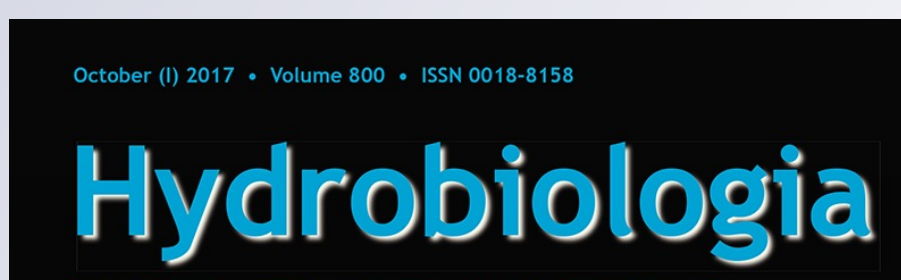

The International Journal of Aquatic Sciences

THEME

Emerging Trends in Aquatic Ecology II

GUEST EDITORS

Koen Martens,

Sidinei M. Thomaz,

Diego Fontaneto \&

Luigi Naselli-Flores

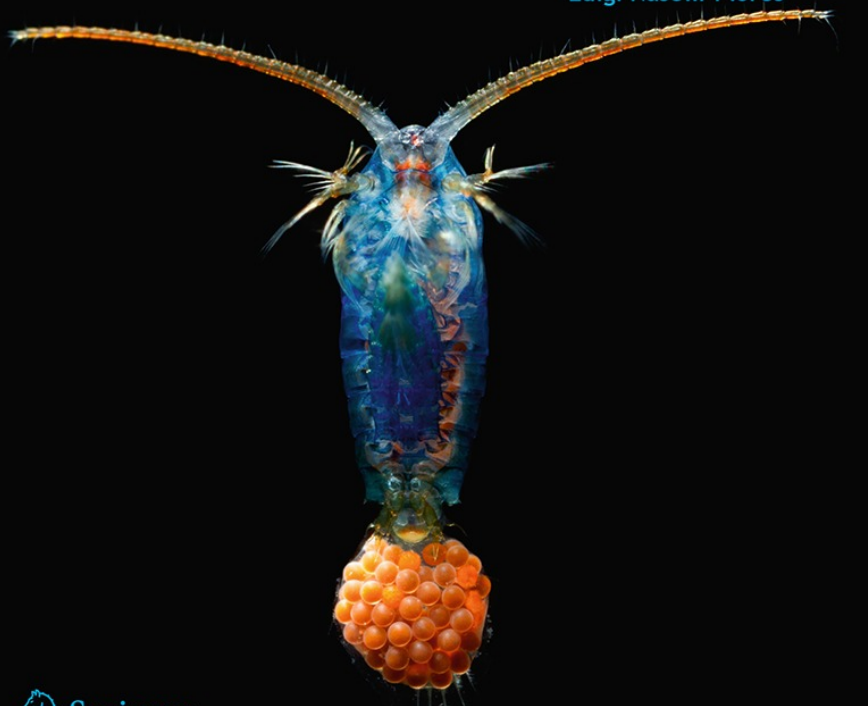

Springer

包 Springer 
Your article is protected by copyright and all rights are held exclusively by Springer International Publishing Switzerland. This eoffprint is for personal use only and shall not be self-archived in electronic repositories. If you wish to self-archive your article, please use the accepted manuscript version for posting on your own website. You may further deposit the accepted manuscript version in any repository, provided it is only made publicly available 12 months after official publication or later and provided acknowledgement is given to the original source of publication and a link is inserted to the published article on Springer's website. The link must be accompanied by the following text: "The final publication is available at link.springer.com". 


\title{
Phytoplankton assemblages in a complex system of interconnected reservoirs: the role of water transport in dispersal
}

\author{
Ren Hu $\cdot$ Xueke Duan $\cdot$ Liang Peng $\cdot$ Boping Han $\cdot$ Luigi Naselli-Flores $\mathbb{C}$
}

Received: 1 January 2017/Revised: 22 February 2017/Accepted: 26 February 2017/Published online: 13 March 2017

(C) Springer International Publishing Switzerland 2017

\begin{abstract}
Phytoplankton in a complex network of reservoirs for drinking water supply was sampled in the dry and flood seasons to understand the role of dispersal through hydrochory and of environmental filters in determining the phytoplankton abundance and composition. The main assumptions tested in the present study are that (i) phytoplankton structure in these waterbodies is strongly dependent on the transportation with the river waters flowing through them and (ii) the importance of this stochastic transportation is decreasing as the connectivity with the river decreases allowing environmental filters to shape phytoplankton structure. The multivariate analysis showed that although phytoplankton was inoculated
\end{abstract}

Guest editors: Koen Martens, Sidinei M. Thomaz, Diego Fontaneto \& Luigi Naselli-Flores / Emerging Trends in Aquatic Ecology II

Electronic supplementary material The online version of this article (doi:10.1007/s10750-017-3146-y) contains supplementary material, which is available to authorized users.

R. Hu $\cdot$ X. Duan $\cdot$ L. Peng $(\bowtie) \cdot$ B. Han Institute of Hydrobiology, Jinan University, Guangzhou 510632, People's Republic of China e-mail: tpengliang@jnu.edu.cn

L. Naselli-Flores $(\bowtie)$

Section of Botany and Plant Ecology, Department of Biological, Chemical and Pharmaceutical Sciences and Technologies, University of Palermo, Via Archirafi 38, 90123 Palermo, Italy

e-mail: luigi.naselli@unipa.it largely by Pearl River water inputs and inflow among the system, the hydraulic architecture of the reservoir network shaped and modulated the composition and abundance of phytoplankton.

Keywords Metacommunity · Phytoplankton assembly · Environmental filters · Water quality · Tropics $\cdot$ Inoculum rate

\section{Introduction}

Ongoing urbanization is a challenge as regards resource availability and distribution to increased number of people concentrating in relatively small areas. Drinking water supply (and its collection and treatment after use) is probably one of the most striking problems to be solved. To achieve the water availability and distribution goals, reservoirs and pipelines have been increasingly built up worldwide (Han \& Liu, 2012; Zarfl et al., 2015). These reservoirs are typically connected in quite complex humanoperated networks with little consideration of their ecosystem dynamics, which is influenced by the hydraulic procedures (Rueda \& Rigosi, 2012; Naselli-Flores, 2014).

Quality of drinking water is a burning issue and a major concern for the management and functioning of megacities, especially because costly treatments are likely needed before water reach final users. 
Eutrophication still represents a major problem worldwide (Ansari et al., 2011), reservoirs are often inherently unable to supply safe and clean drinking water (e.g., Naselli-Flores, 2011, 2014), and expensive treatments are required to ensure sufficient water quality for domestic use. One of the consequences of eutrophication is the proliferation of planktic cyanobacteria, which impair water use because of their actual or potential toxicity (Paerl et al., 2011). Many studies exist on the dynamics of toxic phytoplankton species and strains and on the environmental conditions triggering toxic blooms in man-made lakes. However, in complex reservoir networks, the architecture of the system itself, especially the temporal and spatial distribution of inflows and the way in which water is transported (open channels or pipelines), may play a role in modulating the mechanisms that allow massive dispersal and effective colonization of phytoplankton in different reservoirs (for a review, see Padisák et al., 2016).

The Pearl River Delta (South China) is one of the largest urban agglomerations in the world, and its population is forecasted to exceed 40 million people in this decade (Ma, 2012). On a yearly basis of precipitation, this is a very water-rich region. However, according to monsoonal climate, water quantity strongly fluctuates on a seasonal basis and water storage in reservoirs is necessary to ensure a continuous and regular water supply. To achieve this goal, complex systems of interconnected reservoirs have been established in the last three decades. Several studies investigated water quality issues in this area (Hu et al., 2013, Liu et al., 2013, 2016; Lei et al., 2014; Wang et al., 2014) highlighting a common pattern of eutrophication with high phytoplankton biomass and a high frequency of cyanobacterial blooms.

Altogether these reservoirs and the downstream of Pearl River itself constitute a network of aquatic environments with a variety of connectivity degrees and capability to exchange phytoplankton and nutrients. The phytoplankton inhabiting these complex systems may be considered as a metacommunity, i.e., a set of local communities linked by the dispersal of potentially interacting species (Wilson, 1992). Thus, the species composition in these systems is likely to depend on the hydrological operations that connect/isolate the single water bodies, and the species composition of local communities should result from the interaction of regional and local factors and processes (Ricklefs \& Schluter, 1993).

Several key concepts have been developed in the frame of metacommunity theory to explain the mechanisms shaping the local community structure (Logue et al., 2011). One of the main differences among these models relies on the importance given to the deterministic and stochastic processes (Vergnon et al., 2009). The deterministic perspective assumes that the distribution of species depends on the strength of environmental filters that colonizers have to pass when they reach a new environment (Incagnone et al., 2015). The stochastic approach, or "dispersal-assembly perspective" (Hubbell, 2001), can be considered under different aspects in relation to the environment or organism studied. In case of phytoplankton, dispersal may only occur passively and could be mediated by several physical and biological carriers (Incagnone et al., 2015).

In many interconnected natural aquatic systems (e.g., floodplain lakes), stochastic factors have been considered more important than deterministic ones to explain the phytoplankton composition and structure (Devercelli et al., 2016). In these systems, dispersal is mediated by water movements (hydrochory), which tend to have a strong homogenizing effect on local communities. However, as shown by Xiao et al. (2016) in artificial systems, the connection among reservoirs occurs through pipelines where phytoplankton may be not sufficiently exposed to light to survive transport. In these systems, deterministic factors could have a more important role in shaping the local phytoplankton in different waterbodies.

Little has been known about the tolerance of planktic algae to river water transport in artificial channels and pipelines where algae are exposed to turbulent flow, shear forces, unstable light climate, and flocculation of sediments (Estrada \& Berdalet, 1997). To better understand the role of environmental filters and massive dispersal via water transportation in determining the phytoplankton structure in man-made aquatic systems, we studied an artificial system formed by 18 reservoirs located on the Pearl River Delta and characterized by different degrees of connectivity with the river itself (i.e., from being connected along a distance gradient to totally isolated).

The main assumptions to be tested in the present study were that (i) phytoplankton composition in these 
connected waterbodies is dependent on the passive dispersal operated by the river waters flowing through them and (ii) the importance of this stochastic factor is decreasing as the connectivity with the river decreases allowing environmental filters to shape phytoplankton structure.

\section{Materials and methods}

\section{Description of sites}

A total of 18 reservoirs located on the tropical coastal area of South China (from $20^{\circ} 21^{\prime}$ to $22^{\circ} 0^{\prime} \mathrm{N}$ and from $113^{\circ} 6^{\prime}$ to $113^{\circ} 36^{\prime} \mathrm{E}$ ) were investigated in this study. The locations and connections of the sampled reservoirs, as well as their names and the acronyms used in this study, are shown in Fig. 1 and Table 1. These reservoirs supply drinking water to Zhuhai City and Macao, two urban centers of 2 million people on the delta of Pearl River. The delta is formed by eight main river branches: three of them (named Modao gate, Jiti Gate, and Hutiao Gate) flow across Zhuhai City. Water from these branches is pumped into 12 reservoirs directly connected to the river through pipelines. Another group of six reservoirs is also linked to the water supplying system but they receive water from their own catchments and not from the Pearl River. Altogether, the 18 reservoirs totally supply about $90 \%$ of the drinking water to Zhuhai city and the totality of water to Macao.

Modao Gate is the longest branch of Pearl River $(45 \mathrm{~km})$; it crosses Zhuhai city and 8 reservoirs receiving water from it. The system of pipelines starts at ZUZT pumping station and ZUYI reservoir is the first water body in the uppermost part of the channel. ZUYI is directly connected with YUKE reservoir. The pipe divides into two sections after the GUCA pumping station, which is located $27 \mathrm{~km}$ away from ZUZT. The first section feeds NAPI and ZUXD reservoirs, which supply drinking water to South Zhuhai City and Macao. From these water bodies, another pipe goes north and through NASW pumping station reaches DAJS and FEHS reservoirs. These reservoirs are 50 and $54 \mathrm{~km}$ away from the ZUYI reservoir, respectively, and are closely connected each other through a culvert. The second section goes south to SEDK and YIKE reservoirs. These two reservoirs are used as backup reservoirs and only receive water from the Pearl River once a year at the end of flood season.

Jiti Gate is the second longest branch $(41 \mathrm{~km})$ at the end of Pearl River with three reservoirs receiving

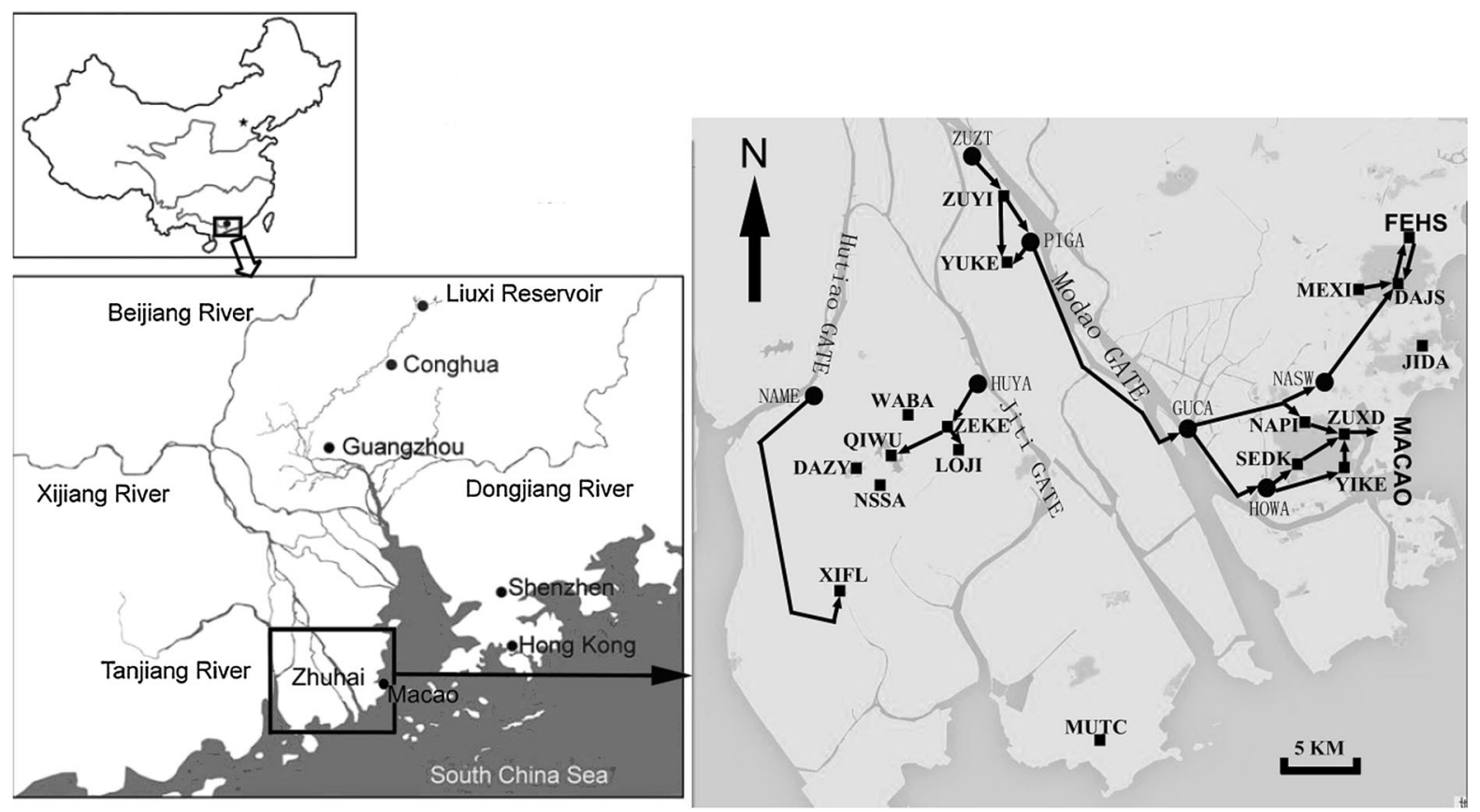

Fig. 1 Map of the studied reservoirs showing the architecture of the water system (round spot pump stations, square spot: reservoirs) 
Table 1 Limnological characteristic of the studied reservoirs

\begin{tabular}{llllll}
\hline Reservoir & Abbreviation & Watershed $\left(\mathrm{km}^{2}\right)$ & Depth $(\mathrm{m})$ & Vol-Max $\left(10^{6} \mathrm{~m}^{3}\right)$ & Connected \\
\hline Jida & JIDA & 1.45 & 12.6 & 1.89 & No \\
Wang Bao & WABA & 3.04 & 13.5 & 2.57 & No \\
Nan Shan & NASA & 4.17 & 11.5 & 2.89 & No \\
Mei Xi & MEXI & 1.74 & 7.2 & 1.37 & No \\
Mu Tou Chong & MUTC & 7.7 & 9.5 & 3.25 & No \\
Da Zhi Yuan & DAZY & 2.37 & 8 & 2.40 & No \\
She Di Keng & SEDK & 2.31 & 21.6 & 1.28 & Yes \\
Long Jin & LOJI & 4.33 & 11.2 & 6.28 & Yes \\
Yin Keng & YIKE & 2.1 & 18.8 & 1.17 & Yes \\
Nan Ping & NAPI & 2.36 & 22.3 & 5.01 & Yes \\
YueKeng & YUKE & 1.13 & 5 & 3.07 & Yes \\
Zhu Yin & ZUYI & 2.8 & 45 & 44.35 & Yes \\
ZengKeng & ZEKE & 2.03 & 16 & 2.32 & Yes \\
Zhu Xian Dong & ZUXD & 2.813 & 13.1 & 1.96 & Yes \\
Qian Wu & QIWU & 10.11 & 13 & 11.66 & Yes \\
Xian Feng Ling & XIFL & 3.28 & 11.5 & 3.24 & Yes \\
Da Jing Shan & DAJS & 5.95 & 12.5 & 8.53 & Yes \\
Feng Huang Shan & FEHS & 9.28 & 13.5 & 10.72 & \\
\hline
\end{tabular}

Depth is measured in front of the dam

water from the HUYA pumping station. The water reaches ZEKE reservoir first and then is quickly moved to QIWU and LOJI reservoirs.

Hutiao Gate is the shortest branch $(26 \mathrm{~km})$, and only XIFL reservoir receives water from this branch through NAME pumping station, after it flows through a $22 \mathrm{~km}$ long pipeline.

ZUYI is the largest and deepest one among the connected reservoirs, and its watershed almost equals the water surface area. YUKE reservoir is the smallest and receives water from both ZUYI reservoir and PIGA pump station. NAPI is a middle-sized reservoir in the system and acts as a transitional water body for both ZUXD and the northern reservoirs. ZUXD supplies about $2-3 \times 10^{5} \mathrm{~m}^{3}$ water (about $10-15 \%$ of its volume) to Macao every day. DAJS and FEHS are the last two large reservoirs located at the end of the pipeline, and they have retention time relatively longer than others.

The six isolated reservoirs do not receive any inflow from the river. All the water in these reservoirs is coming from precipitation in their own watershed. These watersheds are well preserved except the one of DAZY reservoir, where a golf course provides large quantity of fertilizers to the water body. MEXI reservoir is located next to DAJS reservoir and supplies water to it by a culvert but without receiving any water back from DAJS because of its higher altitude. The main morphological features of all the studied reservoirs are summarized in Table 1.

At the end of flood season, the connected reservoirs receive large amount of water from the Pearl River to store and supply drinking water to the urban centers in the dry season. At this time, water level reaches its highest value in all reservoirs. In the dry season, water is not pumped into connected reservoirs due to the inrush of salt tides into the Pearl River, which make it unsuitable for drinking purposes. However, water demand is higher in this period, the water exchange among reservoirs increases, and both connected and isolated reservoirs show their lowest water levels.

Sampling and measurements

The 18 reservoirs and the ZUZT pump station in Pearl River were sampled for phytoplankton at the end of the dry seasons (January) and at the end of the flood season (November) in 2013. Both connected and 
isolated reservoirs were sampled to compare their respective phytoplankton structure. Samples for phytoplankton analyses, chlorophyll $a$ and chemical analyses were collected in the open water area close to the dam, from $0.5 \mathrm{~m}$ beneath the surface the surface (no surface blooms were detected at sampling) to the bottom of the mixing depth, at 1-m intervals. Water for phytoplankton counting was pooled and mixed in a bucket and a subsample of 1,000 ml was fixed with Lugol's solution for species identification and counting.

Water transparency was measured using a Secchi disk (SD) and the euphotic zone was estimated by multiplying water transparency by 2.7 (Cole, 1994). Water temperature, dissolved oxygen, electrical conductivity, salinity, and $\mathrm{pH}$ were measured using a portable multi-parameter probe (Yellow Spring Instruments, Ohio, USA).

Chl- $a$ was measured spectrophotometrically by filtering $500 \mathrm{ml}$ of water through a $0.45-\mu \mathrm{m}$ cellulose acetate filters and extracting the pigment with acetone after repeated freezing and thawing (Lorenzen, 1967; Lin et al., 2005).

Soluble reactive phosphorus (SRP), nitrite $\left(\mathrm{NO}_{2^{-}}\right.$ $\mathrm{N})$, nitrates $\left(\mathrm{NO}_{3}-\mathrm{N}\right)$, ammonium $\left(\mathrm{NH}_{4}-\mathrm{N}\right)$, total nitrogen (TN), and total phosphorus (TP) were analyzed according to A.P.H.A. (2012).

Hydrological data (precipitation, water level, volume, inflow, and outflow) were provided by the Zhuhai Water Group Company. For multivariate analysis, we used the inflow intensity averaged over the 2 weeks prior to each sampling. Mixing depth $\left(z_{\mathrm{m}}\right)$ was estimated from thermal profiles as the water layer from the surface to the depth of maximum thermal discontinuity. Water retention time (WRT) was calculated as the ratio of reservoir volume divided by the average daily outflow measured in the 2 weeks before sampling.

Phytoplankton cell numbers were evaluated by using an inverted microscope according to Utermöhl method and counting was continued up to 400 settling units per sample (Lund et al., 1958). Phytoplankton biomass was estimated using specific biovolumes obtained by geometrical approximations according to Hillebrand et al. (1999). Phytoplankton was identified at the lowest taxonomical rank possible and the definition of genera and major groups of eukaryotic algae is coherent with the recent Systematics (Guiry \& Guiry, 2016). To perform the ecological analyses, species were grouped into Functional Groups (FGs) following Reynolds et al. (2002) and Padisák et al. (2009) and taking into account the recommendations given by Salmaso et al. (2015). The reasons which led to prefer FG classification, among all the available ecological classifications, were analyzed in $\mathrm{Hu}$ et al. (2013).

\section{Data analysis}

Two-way ANOVA (factors: connected/not connected, and dry/flood season) was computed to analyze if the differences observed in the single environmental variables were significant in the studied environments, in the different seasons. Two-way-PERMANOVA was performed on Bray-Curtis distances to evaluate whether connections (connected vs isolated) among reservoirs and seasonality (dry vs flood season) were significantly affecting phytoplankton FGs composition and abundance. The effects of seasonality and connectivity in the studied reservoirs were also tested on a pool of selected environmental variables (Secchi depth, mixing depth, temperature, inorganic nutrient concentrations, WRT) using Euclidean distances after square root transformation. SIMPER analysis was performed to detect the FGs contributing mostly to assemblage dissimilarity among reservoirs. The analyses were run using the software package Past 3.06.

Community ordination was performed using CANOCO 5 (Šmilauer \& Lepš, 2014). Unimodal (Canonical Correspondence Analysis-CCA) or linear (Redundancy Analysis-RDA) methods of ordination with forward selection were used to elucidate the relationships between phytoplankton assemblages and environmental variables. The choice of the ordination method depended on the extent of the Standard Deviation gradient (Legendre \& Legendre, 1998). Although all the identified phytoplankton species were sorted into FGs, only the groups present with a relative biomass greater than $5 \%$ in at least two reservoirs were included in the analyses. Phytoplankton data were square root transformed, whereas environmental data were transformed using the formula $Y_{i}=\log \left(A \times X_{i}+B\right) . A$ and $B$ values were automatically changed by Canoco 5 according to the absolute value of Xi (Šmilauer \& Lepš, 2014). The significance with which environmental variables explain the variance of species data was tested using Monte Carlo simulations with 999 unrestricted 
permutations. Variables were considered to be significant when $P<0.05$.

For the connected reservoirs, an additional variable, the "inoculum rate" (IR), was used to estimate the importance of species transported from the river and/ or from other reservoirs. IR was computed as follows:

$\mathrm{IR}=\frac{V_{\text {in }}-V_{\text {out }}}{V_{\text {res }} \times L_{\mathrm{p}}}\left(\mathrm{km}^{-1}\right)$,

where $V_{\text {in }}$ is the inflow volume and $V_{\text {out }}$ is the outflow volume of the receiving reservoir. The difference between these two variables is considered to be positively related to the amount of algae transported into the reservoirs. $V_{\text {res }}$ is the volume of the receiving reservoir. This value gives an account of the dilution effect. $L_{\mathrm{p}}$ is the length of the pipeline and is considered proportional to the time these algae have to pass in the dark. The amount of algae inoculated was therefore considered inversely proportional to the length of the pipe and to the volume of the reservoir and directly proportional to the amount of inflowing water retained into the system.

\section{Results}

Physical and chemical features in the studied reservoirs

Secchi disk transparency in the studied reservoirs ranged from 0.2 to $3.5 \mathrm{~m}$. In general, it was higher in the dry season than in the flood season (2-way ANOVA: $F=5.39, P<0.03)$ both in the connected and isolated reservoirs (2-way ANOVA: $F=0.16$, $P>0.5)$. The lowest transparency $(0.2 \mathrm{~m})$ was measured in YUKE reservoir in the flood season, when a large quantity of muddy water was pumped into the reservoir. The highest value $(3.5 \mathrm{~m})$ was recorded in SEDK reservoir in the dry season (Fig. 2a).

Mixing depth ranged from 5 to $22.3 \mathrm{~m}$ in the dry season and from 3.5 to $45 \mathrm{~m}$ in the flood period. As shown in Fig. $2 \mathrm{~b}$ and confirmed by 2-way ANOVA $(F<0.25, P>0.4)$, it was generally higher in the dry season and in the connected reservoirs (average value $14.6 \mathrm{~m}$ ) than in the isolated ones (average value $9.3 \mathrm{~m}$ ). The highest differences were recorded in ZUYI, which is the largest among the studied reservoirs.

Total phosphorus concentrations (TP) in the connected reservoirs were higher than those recorded in the isolated ones (Fig. 2c) and seasonal differences were less important (2-way ANOVA: $F=0.19$, $P>0.6$ ) than spatial ones (2-way ANOVA: $F=5.62, \quad P<0.03)$. ZEKE reservoir, which is closely located to the JITI gate branch of Pearl River and is used as a pre-dam for QIWU and LOJI, had the highest TP. Conversely, the isolated WABA reservoir, receiving water from its own relatively undisturbed watershed, showed the lowest value. Among connected reservoirs, the lowest TP values were recorded in YIKE reservoir, because of the lower amount of water received from the Pearl River. SRP concentrations were rather low in all the studied reservoirs, always accounting less than $10 \%$ of the TP.

DIN concentrations showed a wide range of variation (from values around $100 \mu \mathrm{g} \mathrm{l}^{-1}$ in the isolated DAZY reservoir, to values above $2.0 \mathrm{mg}^{-1}$ in the connected ZEKE). The observed pattern was similar to that observed for TP (Fig. 2d) in connected reservoirs, where nutrients are continuously replenished by Pearl River. Conversely, DIN showed a pattern opposite to TP in isolated reservoirs which confirm its role in phytoplankton growth. Also in this case, the observed differences were not significant in the studied seasons (2-way ANOVA: $F=0.18$, $P>0.5)$ compared to those observed in connected and isolated water bodies (2-way ANOVA: $F=5.78$, $P<0.03)$.

Average water retention time (WRT) was generally longer in the isolated reservoirs during the dry season (data not shown). Also in this case, seasonal differences were less important (2-way ANOVA: $F=0.66$, $P>0.4$ ) than spatial ones (2-way ANOVA: $F=6.39$, $P<0.02)$. JIDA reservoir had the longest water retention time since it is an "emergency" water body, seldom used for water supply under normal conditions. The shortest retention times were recorded in a reservoir used as a pre-dam (ZEKE) and in the water body providing daily water supply to Macao (ZUXD).

Spatial and seasonal differences in environmental and biological community among reservoirs

Physical, chemical, and biological data were first analyzed to elucidate if differences in the environmental variables and FGs composition were present in the studied system of reservoirs.

The analysis with PERMANOVA showed that there were both significant seasonal (flood vs dry 

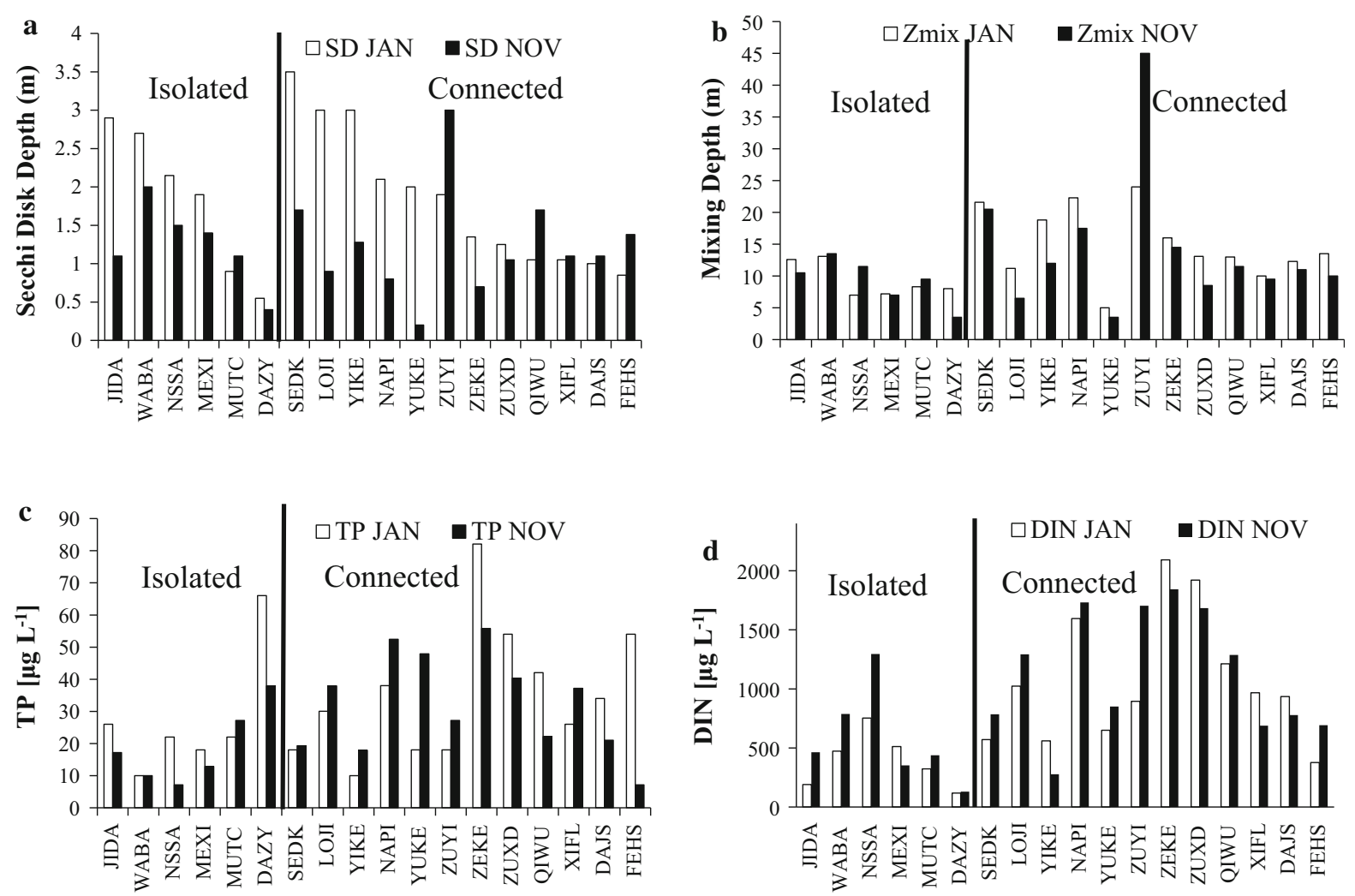

Fig. 2 Patterns of selected environmental variables (a Secchi disk transparency, b mixing depth, c total phosphorus, d dissolved inorganic nitrogen) in the studied reservoirs

season, $P<0.002$ ) and spatial (connected vs isolated, $P<0.001)$ differences among reservoirs according to the recorded values of the environmental parameters (Table 2). Conversely, when using phytoplankton FGs, only a difference between isolated and connected reservoirs was detected $(P<0.001)$, being seasonal difference in their composition and abundance not significant $(P>0.5)$.

Table 2 Two-way PERMANOVA using selected environmental variables and Phytoplankton FGs

\begin{tabular}{lrlll}
\hline Source & df & Mean square & $F$ & $P$ \\
\hline Environmental variables & & & \\
Connection & 1 & 0.054 & 8.2739 & $0.0001^{*}$ \\
Season & 1 & 0.028 & 4.269 & $0.0013^{*}$ \\
Phytoplankton FGs & & & \\
Connection & 1 & 1.558 & 4.9373 & $0.0001^{*}$ \\
Season & 1 & 0.23852 & 0.75587 & 0.5531 \\
\hline
\end{tabular}

$* P<0.01$ Significant
Phytoplankton biomass and distribution of the dominant functional groups

Altogether, 181 phytoplankton species were identified in the studied reservoir network and sorted into 23 functional groups (FGs). Species composition of the FGs in both dry and flood season is reported in Appendix 1-Electronic Supplementary Materials. The table also lists the FGs occurrence in the Pearl River as well as in the connected and in the isolated reservoirs.

Total phytoplankton biomass (Fig. 3a) was much lower in the Pearl River than that recorded in the reservoirs, ranging from $0.24 \mathrm{mg}^{-1}$ (dry season) to $0.56 \mathrm{mg} \mathrm{l}^{-1}$ (flood season). Identified phytoplankton species in the river were grouped in 12 FGs. The number of FGs in the river was lower than that found in the whole system; the dominant groups were similar to those in the reservoirs but group $\mathbf{D}$ which, although found in the Pearl River phytoplankton and represented by the diatoms Stephanodiscus hantzschii 

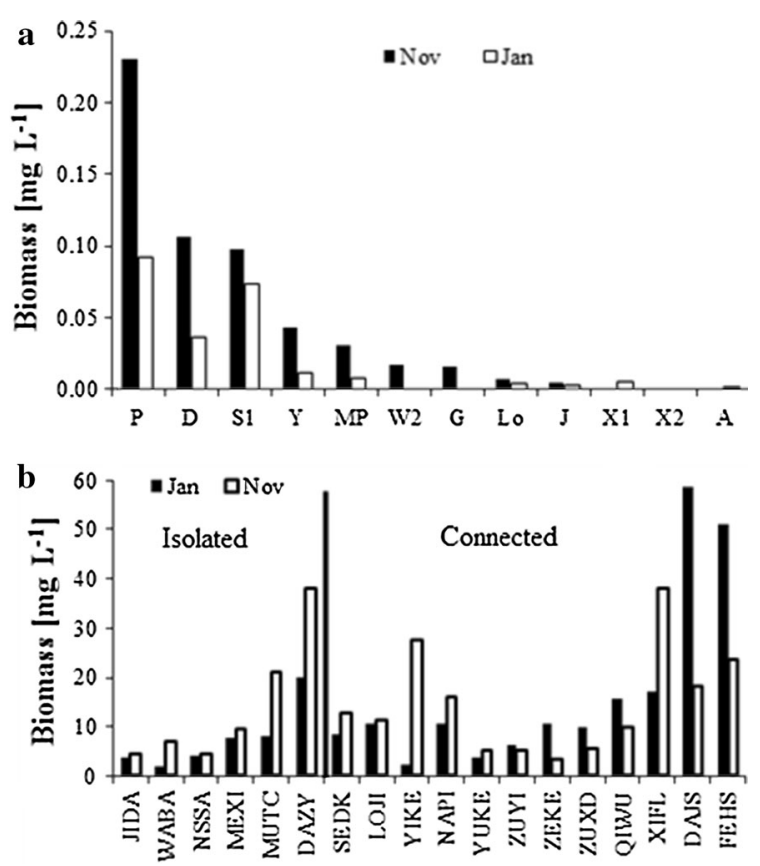

Fig. 3 Phytoplankton biomass in the Pearl River (a) and in the studied reservoirs (b)

Grunow and Actinocyclus normanii (W.Gregory ex Greville) Hustedt, was not present in the reservoirs. The most abundant FGs in the Pearl River were $\mathbf{P}$ (Aulacoseira spp., Closterium spp.), D, $\mathbf{S}_{\mathbf{1}}$ [mainly Pseudanabaena limnetica (Lemmermann) Komárek], and $\mathbf{Y}$ (small dinoflagellates). Among them, $\mathbf{S}_{\mathbf{1}}, \mathbf{P}$, and $\mathbf{Y}$ were the first three FGs contributing to the dissimilarity of the phytoplankton assemblages in the reservoirs. A significantly higher relative abundance of group $\mathbf{S}_{\mathbf{1}}$ was detected in the river in the dry (31.3\%) compared to the flood season (17.6\%) (Appendix 1Electronic Supplementary Materials).

In the isolated reservoirs, phytoplankton total biomass (PB) ranged from 1.9 (WABA) to 38.1 (DAZY) $\mathrm{mg} \mathrm{l}^{-1}$. A relatively lower phytoplankton biomass was recorded in these environments, except in DAZY, which receives fertilizers from a golf yard located in its watershed. The lowest phytoplankton biomass both in the dry and in the flood season was recorded in WABA and JIDA, respectively (Fig. 3b). $\mathbf{N}_{\mathbf{A}}$ (Cosmarium spp.), $\mathbf{L}_{\mathbf{O}}$ (thecate dinoflagellates), and $\mathbf{Y}$ were the dominant FGs at least in one season in all of the isolated reservoirs except DAZY (Appendix 1-Electronic Supplementary Materials). Highest percentage of dominance of $\mathbf{N}_{\mathbf{A}}$ was observed in both seasons (44.8 and $33.9 \%$ in dry and flood season, respectively) in WABA the deepest among isolated reservoir. $\mathbf{L}_{\mathbf{O}}$ was dominant in the dry season in MEXI (72\%) and in the flood season in JIDA (56\%). The highest percentages of $\mathbf{Y}$ were found in the flood season in MEXI (52.9\%), NSSA (35\%), and JIDA $(32 \%)$. $\mathbf{Y}$ representatives were also more abundant in the flood season than in the dry season. $\mathbf{S}_{\mathbf{1}}$ was the dominant FG in DAZY reservoir in both seasons. Other important FGs in the isolated reservoirs included P, J (Pediastrum spp., Scenedesmus spp., Coelastrum spp.), A [Urosolenia longiseta (O. Zacharias) Edlund \& Stoermer, Cyclotella comensis Grunow], F (colonial non-motile green algae), MP (meroplankton), and T [Mougeotia genuflexa (Roth) C.Agardh, Planctonema lauterbornii Schmidle].

Phytoplankton biomass in the connected reservoirs ranged from 2.3 (YIKE) to 58.6 (DAJS) $\mathrm{mg}^{-1}$. XIFL, DAJS, and FEHS, all located at the end of the pipelines, showed the highest values (17.2-58.6 $\mathrm{mg} \mathrm{l}^{-1}$ ) among the connected reservoirs. Conversely, the first two reservoirs on the pipeline, ZUYI and YUKE, had lower biomass values (3.6-6.3 $\mathrm{mg} \mathrm{l}^{-1}$ ). The biomass was also quite low (3.5-10.8 $\mathrm{mg} \mathrm{l}^{-1}$ ) in the two pre-dam reservoirs ZEKE and ZUXD. $\mathbf{S}_{\mathbf{1}}$ was the dominant FG in all the connected reservoirs in the flood season and in the majority $(2 / 3)$ of them in the dry season. In the flood season, the highest percentage of $\mathbf{S}_{\mathbf{1}}$ was recorded in FEHS $(89.7 \%)$ and the lowest in XIFL (16.7\%), both located at the end of the respective pipeline. The group $\mathbf{P}$ was dominant at least in one season in all the connected reservoirs except XIFL and YIKE. The highest percentage of $\mathbf{P}$ representatives was recorded in SEDK $(50.1 \%)$ in the flood season and LOJI (93.3\%) in the dry season, respectively. M (Microcystis spp.) group dominated in the flood season in XIFL reservoir, (PB: $64.2 \%$ ), whereas $\mathbf{C}$ group was the most important FG in the dry season in ZUXD reservoir (PB: 60.4\%). Other abundant FGs in the connected reservoir included $\mathbf{Y}, \mathbf{T}, \mathbf{J}, \mathbf{W}_{\mathbf{1}}$ (free swimming euglenoids), MP, A, B (Cyclotella comta Kützing, $\mathbf{C}$ (Cyclotella meneghiniana Kützing), $\mathbf{L}_{\mathbf{O}}, \mathbf{L}_{\mathbf{M}}$ (large thecate dinoflagellates + Microcystis spp.), and $\mathbf{S}_{\mathbf{N}}$ [Cylindrospermopsis raciborskii (Woloszynska) Seenaya \& Subba Raju]. 
Major FGs contributing to phytoplankton dissimilarity between reservoirs

SIMPER analysis showed that 6 FGs $\left(\mathbf{S}_{\mathbf{1}}, \mathbf{P}, \mathbf{Y}, \mathbf{L}_{\mathbf{M}}, \mathbf{N}_{\mathbf{A}}\right.$ and $\mathbf{L}_{\mathbf{O}}$ ) contributed more than $65 \%$ to the total dissimilarity observed in the samples (Fig. 4). The highest percentage of dissimilarity is due to the group $S_{\mathbf{1}}$, which was dominant in the majority of the connected reservoirs.

The highest similarity in the composition of phytoplankton FGs between each of the studied reservoirs and the Pearl River was recorded in ZUYI reservoir, which is the first one receiving water from the river. The lowest values were found at in the reservoirs located at the end of the longest pipeline (DAJS and FESH). Community similarity was much higher in the flood season than in the dry season, which is consistent with the higher amount of water pumped into the reservoirs in this period. The high similarity recorded in ZUXD reservoir was due to its connection to the closely located HOWA pump station, which provided most of its water in the flood season to supply drinking water to Macao.

The influence of local environmental conditions on the composition of FGs

In connected reservoirs, a gradient of 2.4 SD units was computed and a linear method of ordination (RDA) was used. In isolated reservoirs, the gradient was 3.4 SD units long, so a unimodal method (CCA) was adapted. The analysis was initially run by using all the recorded environmental variables. Forward selection was then used to evaluate the importance of the different variables and to exclude those which were not significantly affecting the variability of FGs.

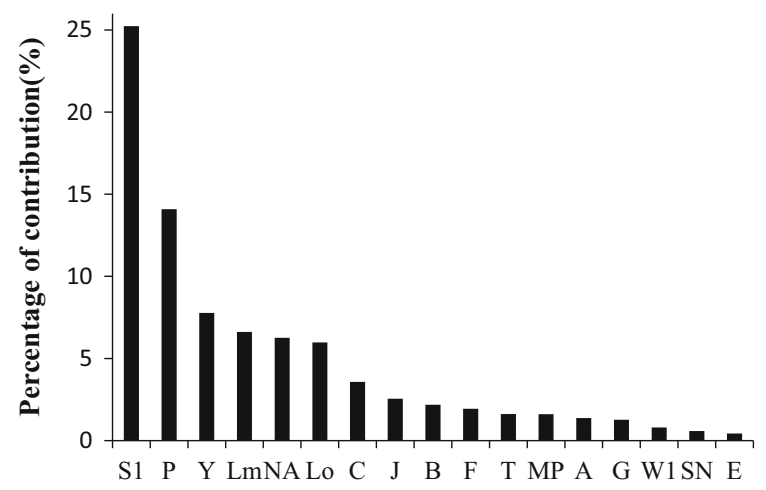

Fig. 4 Contribution of the FGs to dissimilarity among the studied reservoirs (SIMPER analysis, overall average dissimilarity 84)
Only two variables, the inoculum rate (IR) and dissolved inorganic nitrogen (DIN), were found to be significant $(P<0.002)$ explaining $48.6 \%$ of the total variance of FGs in the connected reservoirs (Fig. 5). The variable explaining the highest percentage $(31.5 \%)$ of the phytoplankton FGs was DIN. It was inversely correlated to $\mathbf{S}_{\mathbf{1}}, \mathbf{S}_{\mathbf{N}}$, and $\mathbf{P}(P<0.005)$. IR contributed $24.4 \%$ of the total explanation. The filamentous cyanobacteria group $\mathbf{S}_{\mathbf{1}}$ and $\mathbf{S}_{\mathbf{N}}$ altogether were positively correlated to IR $(P<0.004)$.

When CCA ordination was computed only for the isolated reservoirs, four variables (concentration of $\mathrm{NO}_{3}-\mathrm{N}$, Volume, WRT, and $\left.z_{\text {mix }} / z_{\mathrm{eu}}\right)$ were found to significantly $(P \leq 0.05)$ affect FGs variability in the studied reservoirs. Altogether they explained $57.3 \%$ of the total variance in the subsystem of isolated reservoirs (Fig. 6). The variable explaining the highest percentage (24.7\%) of the phytoplankton FGs variance was nitrate concentration. It was strongly correlated to the first axis and was opposite to $z_{\mathrm{mix}} / z_{\mathrm{eu}}$, which contributed $18.5 \%$ in explaining the total variance of FGs. Both WRT and volume located close to the second axis and explained 21.7 and $16.3 \%$ of the total variance, respectively. FGs tended to distribute along the first axis of the ordination map in a gradient spanning from $\mathbf{S}_{\mathbf{1}}$ to $\mathbf{L}_{\mathbf{O}}$.

\section{Discussion}

Water transportation and its role in the studied system

As widely recognized for microorganisms (Fontaneto \& Hortal, 2012), phytoplankton has a high passive dispersal ability compared to "bigger" components of

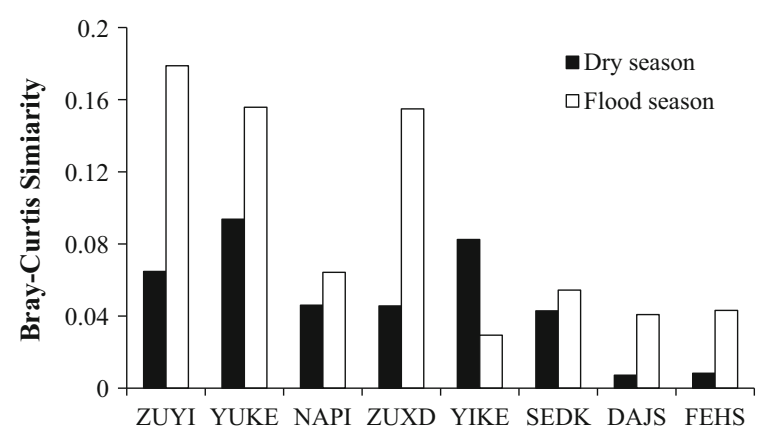

Fig. 5 Similarity of phytoplankton FGs between the Pearl River and the reservoirs arranged according to their distance (length of the pipeline) from the river 


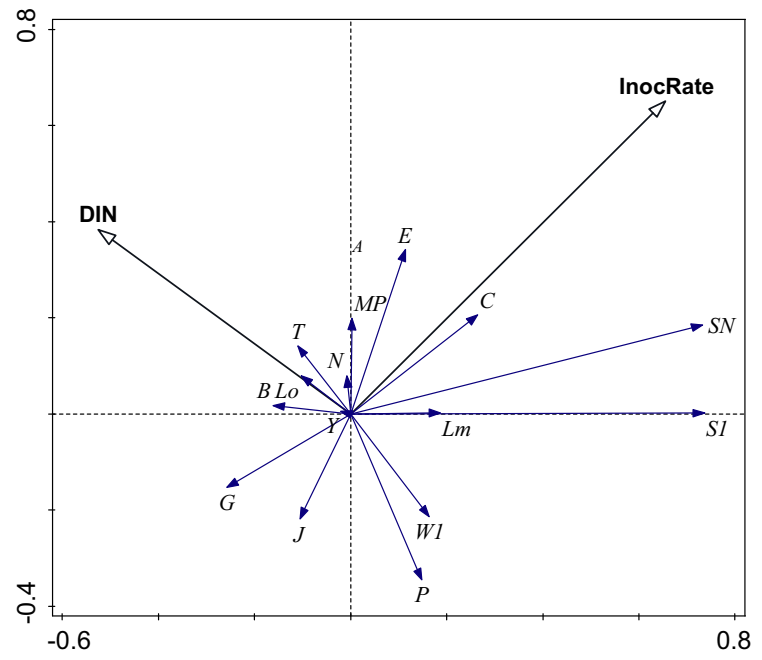

Fig. 6 Ordination biplot (RDA) of functional groups (FGs) and environmental variables in the connected reservoirs. Composition of FGs coda is shown in Appendix 1-Electronic Supplementary Materials

the aquatic biota as macrophytes or fish (Padial et al., 2014). Dispersal of phytoplankton can be mediated by a variety of physical (wind and water) and biological vectors (aquatic birds, mammals, insects, etc.) whose effectiveness might be different in relation to the geographic distribution of water body in a given area (Incagnone et al., 2015; Naselli-Flores et al., 2016; Padisák et al., 2016). Phytoplankton has therefore a true biogeography with well-defined geographic patterns (Naselli-Flores \& Padisák, 2016), which allows for identifying a regional pool of species eventually contributing to establish a metacommunity network. The distribution of these species over the available water bodies in a given territory is therefore mediated by the effectiveness of dispersal agents (contributing to maintain the local community structure and diversity) and by local environmental conditions, which filter the best-fitting species (contributing to the composition of the local community).

In naturally connected ecosystems such as floodplain lakes and complex river systems, water flow is considered the main dispersal vector and both seasonality (duration) and directionality of river flow, as well as water course distances, have an important role in shaping metacommunity in the different ecosystems belonging to the "network" (Liu et al., 2013; Padial et al., 2014; Devercelli et al., 2016). However, in the present study, the network system was formed by human-operated reservoirs and both duration and directionality of water flow were strongly subjected to unpredictable constraints linked to the need of the drinking water supply of urban centers. The complexity of the network system itself was therefore further increased by the applied hydraulic operations as, e.g., unpredictable amount of water pumped from the river through several pumping stations with different locations along the system, and/or water exchange operated not only from the river to the reservoirs but also among reservoirs. These operations therefore lead difficulty in evaluating the effect due to duration and directionality of water flows and as well as the distance effect from the main watercourse. The investigated phytoplankton assemblages showed that many limnological variables were affected by such complexity. As an example, although more water was pumped into the reservoirs during the flood season, contributing to decrease water retention time, this effect could be also due to the water exchange among the water bodies operated during the dry season.

The parameter computed in this study, the inoculum rate, measures the degree of connectivity between reservoirs and was used to partially solve these problems in relation to phytoplankton water-mediated dispersal. It gives an account on the phytoplankton cells/colonies that can be transported by the water flowing in the system. Although it is not quantitative in terms of cells transported, it offers the possibility to rank the reservoirs according to the potentiality to be colonized by viable organism (survivorship depending on the length of the pipeline) in an adequate quantity (depending on the dilution they are subjected).

As already observed in other man-made lakes (e.g., Naselli-Flores, 1999; Naselli-Flores \& Barone, 2005), water movements (i.e., the particular hydraulic procedure applied to reservoir for water management) contribute to modify the physical and chemical characteristics (which may represent environmental filters) of the water bodies. Therefore, hydraulic regime can be regarded as both a stochastic process promoting massive dispersal and a deterministic one because of its influence on water chemical and physical characteristics. As a consequence, it can be difficult to disentangle the role exerted by the different factors which determine the structure of local phytoplankton assemblages. 
Phytoplankton structure in interconnected reservoirs

The ecological classification adopted in this study allows avoiding many drawbacks caused by the use of Linnaean taxonomy in ecology. Taxa may actually include species with very different ecological adaptations, which do not allow to fully clarifying the role exerted by the environmental constraints on the assemblage structure (Salmaso et al., 2015). Conversely, among all the ecological classifications proposed for phytoplankton, the functional groups proposed by Reynolds et al. (2002) are strongly based on the ecological requirements of species and robustly reflect the environmental template (Padisák et al., 2009).

All the connected reservoirs were dominated by the group S1, which collects shade-adapted filamentous cyanobacteria well tolerating turbid and strongly mixed environments. This group, contributed mostly by Pseudanabaena spp., is an important component of the phytoplankton of Pearl River but its dominance in the connected reservoirs is enhanced by its high tolerance to the turbulent conditions and low light that the species experience when transported along the pipelines. This pattern is also shown when the similarity between the composition of phytoplankton between Pearl River and the reservoirs along the network is computed. Two reservoirs, FEHS and DAJS, are strongly dominated by $\mathbf{S 1}$ representatives (89.7 and $87.9 \%$ of total phytoplankton biomass, respectively) although being located at the end of the main and longest underground pipeline connecting the reservoirs. These suggest that $\mathbf{S 1}$ representatives are able to safely travel along the pipeline and easily survive its filtering effect. Moreover, these species are continuously inoculated from the river water flowing into the system as suggested by the computed RDA where the inoculum rate contributes to explain a large percentage of the variance observed in the composition of functional groups. Conversely, as observed by Xiao et al. (2016), other groups, according to their sensitivity to turbulence and low light, are progressively eliminated from the inoculum as the transportation distance increases. In spite of a direct water connection among water bodies, similarity is thus decreasing when the distance that phytoplankton has to travel in the pipeline is increasing. Group $\mathbf{D}$, which was dominant in the Pearl River and included species exclusively occurring in large rivers (e.g., Stephanodiscus hantzschii Grunow), was not detected in any of the studied reservoirs. Group P, which includes shade-adapted diatoms forming filamentous colonies (e.g., Aulacoseira granulata Ehrenberg), was dominant in the reservoirs located at short hydraulic distance from the river. Although other groups commonly found both in the river and in the reservoirs can produce resting stages and their dispersal can also be mediated by biological vectors like aquatic birds (Incagnone et al., 2015), the analyses of phytoplankton composition and abundance in the connected reservoirs strongly suggest that the inoculum coming from the Pearl River has an important role in determining the structure of local phytoplankton assemblages. The pool of species dispersed from the water flow originating from the river is successively "modulated" by the filtering effect exerted by typology of connection existing between the river and each of the connected reservoirs.

Phytoplankton structure in isolated reservoirs

The FGs dominating phytoplankton assemblages of the isolated reservoirs were significantly different from those recorded in those receiving their water from Pearl River. The most characteristic group in these water bodies was the $\mathbf{N}_{\mathbf{A}}$ which includes desmid algae belonging to the genera Cosmarium Corda ex Ralfs, Staurastrum Meyen ex Ralfs, and Staurodesmus Teiling. This group is considered typical of oligomesotrophic, atelomictic environments located in tropical and sub-tropical areas (Souza et al., 2008). The environmental characteristics of the isolated reservoirs well fit the environmental template of this group. Among the isolated reservoirs, only the eutrophic DAZY showed dominant FGs (S1 and P), which were the same as recorded in the connected reservoirs. However, the species contributing to S1 functional group (Limnothrix redekei (Goor) Meffert) was not the same as found in group $\mathbf{S 1}$ in the Pearl River and in the connected reservoirs (Pseudanabaena limnetica (Lemmermann) Komárek). Group Y, mainly formed by cryptophytes and small dinoflagellates, and group $\mathbf{L}_{\mathbf{O}}$, collecting larger dinoflagellates, were also abundant in isolated reservoirs. These water bodies are characterized by oligo-mesotrophic conditions and the mixotrophic representatives of these groups can be more competitive under conditions of lower nutrient 


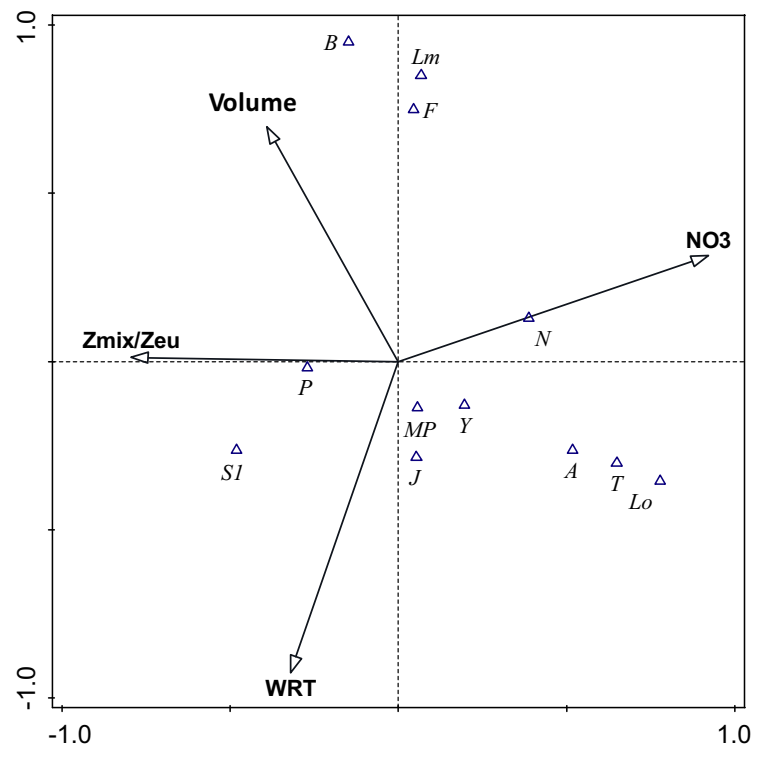

Fig. 7 Ordination biplot (CCA) of functional groups and environmental variables in the isolated reservoirs. Composition of FGs coda is shown in Appendix 1-Electronic Supplementary Materials

availability and, especially for group $\mathbf{Y}$, low grazing pressure (Barone \& Naselli-Flores, 2003).

The difference observed in the phytoplankton composition in the isolated reservoirs compared to connected ones was also supported by the CCA ordination. In contrast to what was observed in connected reservoirs, chemical $\left(\mathrm{NO}_{3}-\mathrm{N}\right)$, physical $\left(z_{\mathrm{mix}} / z_{\mathrm{eu}}\right)$, hydraulic (WRT), and morphological (volume) variables significantly explain the variability observed in the composition of local phytoplankton assemblages. This reveals a more important role exerted by environmental filters, even though dispersal through vectors other than water cannot be excluded (Fig. 7).

\section{Conclusion}

The present study shows that the structure of local phytoplankton assemblage in the connected reservoirs of the studied system was largely depending on the hydraulic architecture (length of pipeline, location of pumping stations, connections among reservoirs) of the system itself. Water flow through the system has therefore strong influence in determining the composition of phytoplankton even though the typology of connection (underground pipelines) has a filtering effect on the pool of available species, which modulate their local abundance. In addition, the unpredictable and conspicuous water movements occurring within the system may have a homogenizing effect on the water quality and contribute to mask the filtering role of local environmental conditions. Some part of the system, although represented by physically independent water bodies, may be regarded as habitats of a meta-ecosystem and stochastic effects can therefore be considered more important than deterministic ones in the process of phytoplankton assembly. Conversely, local environmental conditions appear to be more important in the more isolated water bodies even though stochasticity certainly have a role in allocating species from the regional available pool.

Our conclusions could thus be useful when management plans have to be applied and help in taking decision when water have to be moved from one reservoir to another for supplying drinking water. Reservoirs are complex aquatic ecosystems and not simply water pools for water storage. This complexity is further enhanced when they are connected in highly human-operated networks. As already shown in other reservoirs (e.g., Naselli-Flores \& Barone, 2005; Rigosi \& Rueda, 2012), comprehensive ecological studies are needed for careful planning, the hydraulic operations to be applied, and a thoughtful use of the main water sources has to be reached to improve water quality, reduce treatment costs, and decrease the presence of noxious algal by-products into the water.

Acknowledgements Funding from the Science and Technology Project of Guangdong Province (No. 2013B080500022), the National Science Foundation of China (NSFC) (No. 41403061) and the Science and Technology Project of Guangdong Province (No. 2016A030313098) is acknowledged. Comments from two anonymous reviewers contributed to the improvement of this paper.

\section{References}

Ansari, A. A., S. S. Gill, G. R. Lanza \& W. Rast (eds), 2011. Eutrophication: Causes, Consequences and Control. Springer, Dordrecht.

A.P.H.A., 2012. Standard Methods for the Examination of Water and Wastewater, 22nd edn. American Water Works Association and Water Pollution Control Federation, Washington, DC.

Barone, R. \& L. Naselli-Flores, 2003. Distribution and seasonal dynamics of Cryptomonads in Sicilian water bodies. Hydrobiologia 502: 325-329. 
Cole, G. A., 1994. Textbook of Limnology, 4th edn. Waveland Press, Long Grove.

Devercelli, M., P. Scarabotti, G. Mayora, B. Schneider \& F. Giri, 2016. Unravelling the role of determinism and stochasticity in structuring the phytoplankton metacommunity of the Paraná River floodplain. Hydrobiologia 764: 139-156.

Estrada, M. \& E. Berdalet, 1997. Phytoplankton in a turbulent world. Scientia Marina 61: 125-140.

Fontaneto, D. \& J. Hortal, 2012. Microbial biogeography: is everything small everywhere? In Ogilvie, L. A. \& P. R. Hirsch (eds), Microbial Ecological Theory: Current Perspectives. Caister Academic Press, Norfolk: 87-98.

Guiry, M. D. \& G. M. Guiry, 2016. AlgaeBase. World-Wide Electronic Publication, National University of Ireland, Galway. http://www.algaebase.org; searched on 21 December 2016.

Han, B. \& Z. Liu (eds), 2012. Tropical and Sub-Tropical Reservoir Limnology in China. Theory and Practice. Springer, Dordrecht.

Hillebrand, H., C. D. Dürselen, D. Kirschtel, U. Pollingher \& T. Zohary, 1999. Biovolume calculation for pelagic and benthic microalgae. Journal of Phycology 35: 403-424.

Hu, R., B. P. Han \& L. Naselli-Flores, 2013. Comparing biological classifications of freshwater phytoplankton a case study from South China. Hydrobiologia 701: 219-233.

Hu, R., Q. H. Li, B. P. Han, L. Naselli-Flores, J. Padisák \& N. Salmaso, 2016. Tracking management-related water quality alterations by phytoplankton assemblages in a tropical reservoir. Hydrobiologia 763: 109-124.

Hubbell, S. P., 2001. The Unified Neutral Theory of Biodiversity and Biogeography. Princeton University Press, Princeton, NJ.

Incagnone, G., F. Marrone, L. Robba, R. Barone \& L. NaselliFlores, 2015. How do freshwater organisms cross the "dry ocean"? A review on passive dispersal and colonization processes with a special focus on temporary ponds. Hydrobiologia 750: 103-123.

Legendre, P. \& L. Legendre, 1998. Numerical Ecology, 2nd edn. Elsevier, Amsterdam.

Lei, L., L. Peng, X. Huang \& B. P. Han, 2014 Occurrence and dominance of Cylindrospermopsis raciborskii and dissolved cylindrospermopsin in urban reservoirs used for drinking water supply, South China. Environmental Monitoring and Assessment 186: 3079-3090.

Lin, S. J., L. J. He, P. S. Huang \& B. P. Han, 2005. Comparison and improvement on the extraction method for chlorophyll a in phytoplankton. Chinese Journal of Ecological Science 24: 9-11.

Liu, J., J. Soininen, B. P. Han \& S. A. J. Declerck, 2013. Effects of connectivity, dispersal directionality and functional traits on the metacommunity structure of river benthic diatoms. Journal of Biogeography 40: 2238-2248.

Logue, J. B., N. Mouquet, H. Peter \& H. Hillebrand, 2011. Empirical approaches to metacommunities: a review and comparison with theory. Trends in Ecology \& Evolution 26: 482-491.

Lorenzen, C. J., 1967. Determination of chlorophyll and pheopigments: spectrophotometric equations. Limnology and Oceanography 12: 343-346.
Lund, J. W. G., C. Kipling \& D. Le Cren, 1958. The inverted microscope method of estimating algal numbers and the statistical basis of estimation by counting. Hydrobiologia 11: $143-170$.

Ma, X., 2012. The integration of the city-region of the Pearl River Delta. Asia Pacific Viewpoint 53: 97-104.

Naselli-Flores, L., 1999. Limnological aspects of Sicilian reservoirs: a comparative ecosystemic approach. In Tundisi, J. C. \& M. Straškraba (eds), Theoretical Reservoir Ecology and Its Applications. Backhuys Publishers, Leiden: 283-311

Naselli-Flores, L., 2011. Mediterranean climate and eutrophication of reservoirs: limnological skills to improve management. In Ansari, A. A., S. S. Gill, G. R. Lanza \& W. Rast (eds), Eutrophication: causes, consequences and control. Springer, Dordrecht: 131-142.

Naselli-Flores, L., 2014. Morphological analysis of phytoplankton as a tool to assess ecological state of aquatic ecosystems. The case of Lake Arancio, Sicily, Italy. Inland Waters 4: 15-26.

Naselli-Flores, L. \& R. Barone, 2005. Water-level fluctuations in Mediterranean reservoirs: setting a dewatering threshold as a management tool to improve water quality. Hydrobiologia 548: 85-99.

Naselli-Flores, L. \& J. Padisák, 2016. Blowing in the wind: how many roads can a phytoplanktont walk down? A synthesis on phytoplankton biogeography and spatial patterns. Hydrobiologia 764: 303-313.

Naselli-Flores, L., R. Termine, \& R. Barone, 2016. Phytoplankton colonization patterns. Is species richness depending on distance among freshwaters and on their connectivity? Hydrobiologia 764: 103-113.

Padial, A. A., F. Ceschin, S. A. J. Declerck, L. De Meester, C. C. Bonecker, F. A. Lansac-Tôha, L. Rodrigues, L. C. Rodrigues, S. Train, L. F. M. Velho \& L. M. Bini, 2014. Dispersal ability determines the role of environmental, spatial and temporal drivers of metacommunity structure. PLoS ONE 9(10): e111227.

Padisák, J., L. O. Crossetti \& L. Naselli-Flores, 2009. Use and misuse in the application of the phytoplankton functional classification: a critical review with updates. Hydrobiologia 621: 1-19.

Padisák, J., G. Vasas \& G. Borics, 2016. Phycogeography of freshwater phytoplankton: traditional knowledge and new molecular tools. Hydrobiologia 764: 3-27.

Paerl, H. W., H. Xu, M. J. McCarthy, G. Zhu, B. Qin, Y. Li \& W. S. Gardner, 2011. Controlling harmful cyanobacterial blooms in a hyper-eutrophic lake (Lake Taihu, China): the need for a dual nutrient (N \& P) management strategy. Water Research 45: 1973-1983.

Reynolds, C. S., V. Huszar, C. Kruk, L. Naselli-Flores \& S. Melo, 2002. Towards a functional classification of the freshwater phytoplankton. Journal of Plankton Research 24: 417-428.

Ricklefs, R. E. \& D. Schluter, 1993. Species Diversity in Ecological Communities. Historical and Geographical Perspectives. The University of Chicago Press, Chicago.

Rigosi, A. \& F. Rueda, 2012. Hydraulic control of short-term successional changes in the phytoplankton assemblage in stratified reservoirs. Ecological Engineering 44: 216-226. 
Salmaso, N., L. Naselli-Flores \& J. Padisák, 2015. Functional classifications and their application in phytoplankton ecology. Freshwater Biology 60: 603-619.

Šmilauer, P. \& J. Lepš, 2014. Multivariate Analysis of Ecological Data using Canoco 5, 2nd edn. Cambridge University Press, Cambridge.

Souza, M. B. G., C. F. A. Barros, F. A. R. Barbosa, É. Hajnal \& J. Padisák, 2008. The role of atelomixis in phytoplankton assemblages' replacement in Dom Helvécio Lake, SouthEast Brazil. Hydrobiologa 607: 211-224.

Vergnon, R., N. K. Dulvy, \& R. P. Freckleton, 2009. Niches versus neutrality: uncovering the drivers of diversity in a species-rich community. Ecology Letters 12: 1079-1090.

Wang, C., X. Li, Z. Lai, Y. Li, A. Dauta \& S. Lek, 2014 Patterning and predicting phytoplankton assemblages in a large subtropical river. Fundamental and Applied Limnology 185: 263-279.

Wilson, D. S., 1992. Complex interaction in metacommunities, with implications for biodiversity and higher levels of selection. Ecology 73: 1984-2000.

Xiao, L.-J., R. Hu, L. Peng, L.-M. Lei, Y. Feng \& B.-P. Han, 2016. Dissimilarity of phytoplankton assemblages in two connected tropical reservoirs: effect of water transportation and environmental filters. Hydrobiologia 764: 127-138.

Zarfl, C., A. E. Lumsdon, J. Berlekamp, L. Tydecks \& K. Tockner, 2015. A global boom in hydropower dam construction. Aquatic Sciences 77: 161-170. 